\title{
Personality and well-being in Black and White South African emerging adults
}

\author{
Jan Alewyn Nel ${ }^{1 \cdot A, B, D, E, F}$, Byron G. Adams ${ }^{2 \cdot A, B, C, E}$, Fons F. R. van de Vijver ${ }^{3 \cdot E}$, Sumaya Laher ${ }^{4 \cdot B}$, \\ Johann Louw ${ }^{5 \cdot B}$, Lerato M. Makhale ${ }^{6 \cdot B}$, Luzelle Naude ${ }^{7 \cdot B}$, Florance Tadi ${ }^{7 \cdot B}$ \\ 1: University of Pretoria, South Africa \\ 2: Tilburg University, The Netherlands and University of Johannesburg, South Africa \\ 3: Tilburg University, The Netherlands and North-West University, South Africa and University of Queensland, Australia \\ 4: University of Witswatersrand, South Africa \\ 5: University of Cape Town, South Africa \\ 6: University of Western Cape, South Africa \\ 7: University of the Free State, South Africa
}

BACKGROUND

In the last ten years, the South African Personality Inventory (SAPI) has been developed as an indigenous measurement of personality for the multi-cultural environment of South Africa. The aim of the SAPI is to assess personality in an unbiased and equivalent way. For the purpose of this study, we used an 82-item version of the SAPI which measures nine factors (Conscientiousness, Emotional Stability, Extraversion, Facilitating, Integrity, Intellect, Openness, Relationship Harmony and Soft-heartedness).

\section{PARTICIPANTS AND PROCEDURE}

A cross-sectional survey was conducted using the SAPI, the General Health Questionnaire and the Brief Multidimensional Student Life Satisfaction Scale. A purposive sample was drawn from Black and White emerging adults $(N=990)$. We assessed the relationship between personality aspects and well-being across groups in a multiple group structural equation model (SEM) using the SPSS and AMOS programs.

\section{RESULTS}

Black emerging adults showed evidence of more individualistic-inclined personality features, while the White emerging adults seem to demonstrate more collectivistic features. In terms of health, the White emerging adults experience more life satisfaction than their Black counterparts. Conscientiousness, emotional stability, extraversion, facilitating and openness predict well-being among emerging adults.

\section{CONCLUSIONS}

This study contributes to expanding the nomological network of the SAPI, and it enhances knowledge pertaining to the link between personality and well-being of emerging adults in South Africa. Understanding which factors contribute to poor mental health and lack of life satisfaction may lead to innovation programmes for emerging adults to assist them in dealing with negative health outcomes possibly associated with living in multicultural contexts.

\section{KEY WORDS}

personality; well-being; South African Personality Inventory; emerging adults; South Africa

Corresponding AUthor - Prof. Jan Alewyn Nel, University of Pretoria, PO Box x20, Hatfield 0028 Pretoria, South Africa, e-mail: alewyn.nel@up.ac.za

AUthors' CONTRIBUtion - A: Study design - B: Data collection - C: Statistical analysis - D: Data interpretation .

E: Manuscript preparation $\cdot F$ : Literature search $\cdot$ G: Funds collection

to cite this ARTICLE - Nel, J. A., Adams, B. G., van de Vijver, F. J. R., Laher, S., Louw, J., Makhale, L. M., Naude, L.,

\& Tadi, F. (2017). Personality and well-being in Black and White South African emerging adults. Current Issues in

Personality Psychology, 5(1), 11-20.

RECEIVED 15.05.2016 · REVIEWED 01.06.2016 · ACCEPTED 16.11.2016 · PUBLISHED 13.12.2016 


\section{BACKGROUND}

How you are as a person seems to have considerable influence on how well you are doing. Personality could therefore be argued to have a considerable impact on how well people do in terms of their psychological functioning. While it is clear that personality is positively associated with well-being (Ozer \& Benet-Martinez, 2006), there is very little evidence of this within the South African context, where assessment is quite complex and challenging because of the multi-cultural and multi-linguistic nature of the society.

Although well-being studies in South Africa are abundant (see Posel \& Casale, 2016), quite a few studies focus on ethnic differences in the experience of well-being (see Neff, 2007). Furthermore, a cross-ethnic comparative study in the experience of well-being and its relationship with personality was never done before in South Africa. The objective of this study is therefore to examine the association of personality aspects as measured by a South African developed personality instrument, the South African Personality Inventory (SAPI; Hill et al., 2013; Nel et al., 2012; Valchev et al., 2013) with well-being. In the following section, a review of relevant literature is presented.

\section{PERSONALITY AND MEASUREMENT IN SOUTH AFRICA}

Neill (2003) stated that personality is the unique psychological composition of a person. This includes personality conceptions that are inferred from and can predict and account for patterns of thoughts, feelings, and actions. Personality conceptions are thoroughly assessed by employing various self-report questionnaires (16PF, 15FQ, OPQ, etc.) or projective measures (i.e., Rorschach technique). In the context of South Africa, determining the personality composition of an individual has mainly been done by employing various instruments from Western countries which were adapted for use in South Africa (Meiring, van de Vijver, \& Rothmann, 2006; Nel et al., 2012).

De Raad et al. (2014) identify Africa, South America and Asia in general as societies where very little is known about personality trait structures, and therefore more caution is needed when stating that personality is a universal phenomenon. Some research has shown that personality instruments are limited for use in South Africa and need continual refinement (Fetvadjiev, Meiring, van de Vijver, Nel, \& Hill, 2015; Taylor \& De Bruin, 2005; Van Zyl, 2014). Cultural and language bias and inequalities seem to be the major problems (Fetvadjiev et al., 2015; Meiring, van de Vijver, Rothmann, \& Barrick, 2005). This emphasises the need to explore personality in South Africa using indigenous methodology in order to overcome these limitations.
The South African Personality Inventory project (SAPI; Hill et al., 2013; Nel et al., 2012; Valchev et al., 2013) began in 2005 to overcome the issues identified concerning personality assessment in South Africa. This project aims to develop an indigenous personality assessment that caters for all the multi-cultural and multi-linguistic groups within South Africa. The SAPI team utilised a modified lexical approach in the study of personality (Valchev et al., 2011). When using the lexical approach in totality, dictionaries are usually the traditional method to generate personality conceptions from a specific language (Saucier \& Goldberg, 2001). However, it was not possible in South Africa since some of the indigenous African languages do not have dictionaries available. Therefore, a modified lexical approach (Nel et al., 2012; Valchev et al., 2011) was used where interviews were conducted in the native language of the participant to generate personality conceptions for each language. These personality conceptions as deemed important by all linguistic groups in South Africa were identified and compared. This led to nine overall factors shared by all linguistic groups, which were labelled as Conscientiousness, Emotional Stability, Extraversion, Facilitating, Integrity, Intellect, Openness, Relationship Harmony and Soft-heartedness.

As can be seen, the nine factors seem distinct from the traditional Big Five, although some similarities can be detected. The traditional Big Five consist of Agreeableness, Conscientiousness, Extraversion, Neuroticism and Openness to Experience, and are seen as more individualistic in orientation (Laher, 2013). According to Nel and colleagues (2012), although Conscientiousness, Emotional Stability, and Extraversion are the most recognizable factors of the SAPI in comparison to the Big Five, it seems that some other shared elements can be detected. Intellect and Openness from SAPI associate the most with the Openness to Experience factor of the Big Five, while Integrity is seen as a sub-dimension of Conscientiousness (Lee \& Ashton, 2008). Additionally, although Facilitating can be seen as an indigenous concept, some elements can be shared with the Agreeableness factor of the Big Five (along with the Relationship Harmony and Soft-heartedness factors) (Nel et al., 2012).

\section{PERSONALITY IN A CROSS-CULTURAL CONTEXT}

A few studies have investigated personality differences among groups, as well as aiming to validate personality structures within South Africa (Laher \& Cockcroft, 2014; Wallis \& Birt, 2003). Some of these studies identified differences in personality structures among the various language and/or race groups. In recent research conducted by Adams, van 
de Vijver and De Bruin (2012) and Valchev and colleagues (2013) it was found that vast differences do exist between the main ethnic groups of South Africa. Adams and colleagues (2012), for instance, found that White participants are more individualistically oriented in their identity descriptions, while Black participants were inclined to be more collectivistic. This is consistent with a previous study done by Booysen (2001) where she tested for individualistic and collectivistic orientation among Black and White employees. She found that Black employees scored higher on social relational aspects than White employees. However, more recent studies found that the differences between Black and White South Africans pertaining to individualistic and collectivistic elements seem to be dwindling (Feldman \& Msibi, 2014; Govind, 2015). Donoghue, Strydom, Andrews, Pentecost, and De Klerk (2015) stated more definitely that it seems that cultural swapping is taking place between Black and White South Africans. Laher (2013) made a strong case in which she stated that previously oppressed groups (such as Black South Africans) usually adopt collectivistic notions in order to function in an abnormal society. Those notions may be diminished when political changes occur.

Returning to personality, the Big Five dimensions were found to be more salient among the White population than the Black population in previous studies (Heuchert, Parker, Strumpf, \& Myburgh, 2000; Ramsay, Taylor, De Bruin, \& Meiring, 2008). Studies by both Taylor (2000) and Matsimbi (1997) in South Africa found that Openness to Experience and Emotional Stability were not clearly discernible among the Black individuals. However, greater equivalence pertaining to the Big Five dimensions was found in later studies in South Africa, with little to no differences (Fetvadjiev et al., 2015; Laher, 2013). This is consistent with the arguments made in the previous paragraph concerning individualistic and collectivistic elements.

\section{PERSONALITY AND WELL-BEING}

Well-being research in South Africa has been conducted extensively in recent years (e.g., Bruwer, 2016; Nel, Nel, Adams, \& De Beer, 2015; Van Jaarsveld, 2015). Seligman (2012) sees well-being as an element of positive psychology, and defines it as the overall constructive physical, psychological, and social functioning of an individual. According to Anglim and Grant (2014) and Erdogan, Bauer, Truxillo and Mansfield (2012), the composition of a person (dominant traits) affects a person' overall well-being. Both studies state that the Big Five personality factors are definite predictors of overall well-being of individuals. More specifically, research suggests that Neuroticism, Extraversion, and Conscientiousness have the most significant relationships with well-being, followed by Openness and Agreeableness (Cropanzano \& Dasborough, 2015). Cropanzano and Dasborough (2015) specify that some personality traits (i.e., Extraversion, Neuroticism), although showing regular patterns, are dependent on moods (positive vs. negative affect), and it may influence overall well-being inferences made at one point of time.

Pertaining to SAPI research, it was found that Neuroticism, Extraversion, Conscientiousness, and Intellect-Openness showed the strongest association with well-being (Bruwer, 2016). It seems that social-relational aspects (Facilitating, Integrity, Relationship harmony and Soft-heartedness) showed the weakest association with overall well-being. Life satisfaction is seen as a component of overall well-being. Steel, Schmidt, and Schultz (2008) found that several Big Five elements predict life satisfaction. Their findings showed evidence that Neuroticism (negatively related) showed the strongest association with life satisfaction, while Agreeableness, Extraversion and Conscientiousness showed moderate but adequate levels of influence. Openness was the only factor of the Big Five that showed little evidence of influencing life satisfaction.

Concerning cross-cultural studies on well-being, little difference has been identified pertaining to overall well-being, while life satisfaction as a dimension of overall well-being has been researched in cross-cultural South Africa (Ebrahim, Botha, \& Snowball, 2013; Schatz, Angotti, Madhavan, \& Sennott, 2015). It was found that the White population shows better life satisfaction than the Black population (Ebrahim et al., 2013).

\section{THE PRESENT STUDY}

South Africa comprises four main ethnic groups (Black, Coloured, Indian/Asian, and White), and eleven official languages (Afrikaans, English, isiNdebele, isiXhosa, isiZulu, Northern Sotho, Setswana, Southern Sotho, SiSwati, Tshivenda and Xitsonga) (Statistics South Africa, 2011). Since the first democratic elections in South Africa in 1994 many factors have questioned fair and unbiased assessment in South Africa (Meiring et al., 2005; Nel et al., 2012; Valchev et al., 2013). The elections led to the inclusion of previous disadvantaged groups in opportunities which were not accessible to them before 1994, such as tertiary education, labour force and the chance to vote (Meiring et al., 2005). Because of this, the Employment Equity Act was adopted; it states clearly that all measurements should be valid, reliable, unbiased and equivalent across all cultural and linguistic groups within South Africa (Hill et al., 2013).

Assessment, and particularly personality assessment, was usually done with imported measure- 
ments which were applicable only for the White ethnic group, and were translated from English to Afrikaans (Ramsay et al., 2008). From the research done, it seems no personality assessments adhere to these new requirements of the Employment Equity Act (EEA), even 22 years after apartheid (Nel et al., 2016). Thus it is the objective of the SAPI project to adhere to these requirements. We are in the process of building the nomological network of this new personality assessment (Bruwer, 2016). For the purpose of this study, we want to determine which SAPI factors can predict well-being as an outcome among Black and White emerging adults in South Africa.

\section{PARTICIPANTS AND PROCEDURE}

\section{PARTICIPANTS}

Data were collected as part of a larger study on Identity, Personality, Culture and Well-being in South Africa from undergraduate students from several universities. The sample consisted of 990 South African emerging adults $\left(74.04 \%\right.$ females, $M_{\text {age }}=19.95$ years, $S D=1.66)$, who self-identified as Black $(n=390$, $77.43 \%$ females, $M_{\text {age }}=20.29$ years, $\left.S D=1.98\right)$ or White $\left(n=600,71.83 \%\right.$ females, $M_{\text {age }}=19.73$ years, $S D=1.37)$. Chi-square analysis indicated no significant differences across ethnocultural groups in terms of gender $\left(\chi^{2}(1, N=989)=3.70, p=.054\right)$, while Black participants were found to be older than the White participants $\left(F(1,628)=27.34, p=.001, \eta_{\mathrm{p}}^{2}=.03\right)$.

\section{MEASURES}

The measures were administered to participants in English. The measures included a sociodemographic questionnaire, the South African Personality Inventory (SAPI), General Health Questionnaire (GHQ-12) and the Brief Multidimensional Student Life Satisfaction Scale.

Sociodemographic questionnaire. Participants provided their age, gender, and their ethnocultural group.

Personality. We measured personality by using items of the SAPI scale (Hill et al., 2013). We selected 82 items from the item pool and asked participants, using a seven-point Likert-type scale ranging from 1 (Strongly disagree) to 7 (Strongly agree), to indicate the extent to which each item described them on the nine clusters: Soft-heartedness (11 items, with 4 items reverse scored); Relationship Harmony (11 items, with 5 items reverse scored); Openness (11 items); Extraversion (11 items, with 2 items reverse scored and 1 item removed); Emotional Stability (11 items, 5 items reverse scored and 1 item removed); Integrity (6 items); Intellect (6 items); Facilitating (4 items); and Conscientiousness (11 items). This is a self-rating scale. A study conducted by Nel and colleagues (2015) reported alphas of between .63 to .79 using the scale: Extraversion $(\alpha=.67)$; Facilitating $(\alpha=.68)$; Integrity $(\alpha=.67)$; Intellect $(\alpha=.63)$; Openness $(\alpha=.63)$; Relationship harmony $(\alpha=.68)$; and Soft-heartedness $(\alpha=.79)$. Lance, Butts and Michels (2006) stated that the new instruments usually generate a lower value than the normal cut-off $(>.70)$. According to Black and Porter (1996), an $\alpha$ coefficient of .60 or higher is considered adequate in exploratory research.

Well-being. We measured well-being by evaluating life satisfaction and poor mental health. Students completed the 6-item Brief Multidimensional Student Life Satisfaction Scale (Huebner, Nagle, \& Suldo, 2003) using a 7-point Likert-type scale ranging from 1 (Terrible) to 7 (Excellent). An example item is "I would describe my satisfaction with myself as". This measure is unidimensional. Emerging adults also reported recent minor psychological problems (to detect poor mental health) on the 12-item General Health Questionnaire (GHQ-12, Goldberg, 1972). An example item is "Being able to concentrate on what you're doing", which is rated on a 4-point Likert scale ranging from 1 (Better than usual) to 4 (Much less than usual). This measure is unidimensional.

\section{RESULTS}

\section{PRELIMINARY ANALYSES}

The Expectation-Maximization algorithm (Dempster, Laird, \& Rubin, 1977, using SPSS Version 23) was used to impute small missing data. Little's Missing Completely at Random (MCAR) was significant, $\chi^{2}(24814, N=989)=29333.27, p<.001$. Chi-square analyses are known to be sensitive to sample size, so it is recommended to compute the normed $\chi^{2}$ $\left(\chi^{2} / d f\right)=1.18$, which indicates that data can be treated as MCAR if smaller than 2 (Bollen, 1989; Klimstra et al., 2010; Schwartz et al., 2011). Internal consistencies represented by the Cronbach $\alpha$ and structural invariance (indicated by Tucker's phi) presented in Table 1 for all measures were acceptable (van de Vijver \& Leung, 1997). Pertaining to testing structural invariance, a Tucker's phi value of .90 or higher indicates acceptable congruence between the two ethnocultural groups.

\section{DESCRIPTIVE STATISTICS}

We conducted a multivariate analysis of variance (MANOVA) with two ethnocultural groups (Black and White) as independent variables. We used personality and well-being (life satisfaction and mental health) as dependent variables. The multivariate effects were 
Jan Alewyn Nel, Byron G. Adams, Fons J. R. van de Vijver, Sumaya Laher, Johann Louw, Lerato M. Makhale, Luzelle Naude, Florance Tadi

Table 1

Scale reliabilities and structural invariance across ethnocultural groups

\begin{tabular}{|c|c|c|c|c|}
\hline & Final Items & Black EA & White EA & Tucker's phi \\
\hline \multicolumn{5}{|l|}{ Personality } \\
\hline Soft-heartedness & 11 & .83 & .86 & 0.99 \\
\hline Relationship harmony & 11 & .72 & .74 & 0.96 \\
\hline Openness & 11 & .74 & .75 & 0.99 \\
\hline Extraversion & 10 & .70 & .76 & 0.97 \\
\hline Emotional stability & 10 & .70 & .74 & 0.99 \\
\hline Integrity & 6 & .64 & .67 & 1.00 \\
\hline Intellect & 6 & .77 & .79 & 1.00 \\
\hline Facilitating & 4 & .80 & .74 & 1.00 \\
\hline Conscientiousness & 11 & .85 & .86 & 1.00 \\
\hline \multicolumn{5}{|l|}{ Well-being } \\
\hline Life satisfaction & 6 & .77 & .85 & 0.99 \\
\hline (Poor) Mental health & 12 & .88 & .90 & 1.00 \\
\hline
\end{tabular}

Note. EA - Emerging Adults. Measurement invariance was not calculated for intergroup relation subscales as different target groups were used to measure in-group and out-group orientations.

significant for the two ethnocultural groups (Wilks' $\left.\lambda=.87, F(11,979)=13.79, p<.001, \eta_{\mathrm{p}}{ }^{2}=.13\right)$. Table 2 presents univariate results, with means and standard deviations and for Black and White emerging adults. Groups differed significantly across all personality aspects, except for Integrity. It seems that the Black group experiences Conscientiousness, Facilitating, Intellect and Openness more than the White group, while the White group experiences Emotional stability, Extraversion, Relational harmony, and Soft-heart-

Table 2

Ethnocultural group mean differences for identity and intergroup relations

\begin{tabular}{|c|c|c|c|c|}
\hline & \multirow{2}{*}{$\begin{array}{c}\text { Black EA } \\
M(S D) \\
\end{array}$} & \multirow{2}{*}{$\begin{array}{c}\text { White EA } \\
M(S D)\end{array}$} & \multicolumn{2}{|c|}{ Ethnocultural group } \\
\hline & & & $F(3,386)$ & $\eta_{p}^{2}$ \\
\hline \multicolumn{5}{|l|}{ Personality } \\
\hline Soft-heartedness & $2.27(0.89)$ & $2.40(0.91)$ & $4.60^{*}$ & .01 \\
\hline Relationship harmony & $2.68(0.79)$ & $2.81(0.77)$ & $6.57^{*}$ & .01 \\
\hline Openness & $5.48(0.74)$ & $5.34(0.75)$ & $8.08^{* *}$ & .01 \\
\hline Extraversion & $4.99(0.83)$ & $5.11(0.84)$ & $5.41^{*}$ & .01 \\
\hline Emotional stability & $2.90(0.83)$ & $3.13(0.82)$ & $17.69^{* * *}$ & .02 \\
\hline Integrity & $5.52(0.82)$ & $5.57(0.78)$ & 1.12 & .00 \\
\hline Intellect & $5.51(0.80)$ & $5.36(0.83)$ & $8.36^{* *}$ & .01 \\
\hline Facilitating & $5.66(0.96)$ & $5.48(0.88)$ & $10.08^{* *}$ & .01 \\
\hline Conscientiousness & $5.59(0.83)$ & $5.48(0.84)$ & $4.01^{*}$ & .00 \\
\hline \multicolumn{5}{|l|}{ Well-being } \\
\hline Life satisfaction & $5.42(0.90)$ & $5.71(0.94)$ & $23.24^{* * *}$ & .02 \\
\hline (Poor) Mental health & $1.04(0.62)$ & $1.01(0.57)$ & 0.59 & .00 \\
\hline
\end{tabular}


edness the most. White emerging adults experience the most life satisfaction, while both Black and White emerging adults experience (poor) mental health the same way.

\section{PERSONALITY AND WELL-BEING}

We tested a multigroup structural equation multiple indicators multiple causes (MIMIC) model in which the relationship between personality aspects related to well-being. With all parameters constrained to be equal for both groups, the measurement residuals model was the most parsimonious model with good fit, $\chi^{2}(74, N=991)=185.81, p<.001, \chi^{2} / d f=2.51, \mathrm{CFI}=.98$, RMSEA $=.04(\mathrm{Hu} \&$ Bentler, 1999), as can be seen in Table 3. As illustrated in Figure 1, we found that Emotional Stability, Extraversion, Soft-heartedness, and Conscientious were positive indicators of latent well-being indicated by life satisfaction and (poor) mental health. Facilitating was negatively associated with well-being, whereas relationship harmony, openness, integrity and intellect were not associated with well-being. All personality aspects as measured by the SAPI were significantly related to each other.

\section{DISCUSSION}

The purpose of this study was to determine how personality, as measured by SAPI, influences certain well-being outcomes in Black and White emerging

Table 3

Fit statistics for multigroup model

\begin{tabular}{lccccccc}
\hline Model & $\chi^{2} / d f$ & AGFI & TLI & CFI & RMSEA & $\Delta \chi^{2}$ & $\Delta d f$ \\
\hline Unconstrained & 3.79 & .91 & .95 & .99 & .05 & - & - \\
Measurement weights & 3.88 & .91 & .95 & .99 & .05 & $5.46^{*}$ & 1 \\
Structural weights & 3.23 & .93 & .96 & .99 & .05 & $17.97^{*}$ & 9 \\
Structural covariances & 2.46 & .94 & .97 & .98 & .04 & $90.72^{* * *}$ & 45 \\
Structural residuals & 2.43 & .94 & .97 & .98 & .04 & 0.28 & 1 \\
Measurement residuals & 2.51 & .94 & .94 & .98 & .04 & $10.80^{* *}$ & 2 \\
\hline
\end{tabular}

Note. AGFI - adjusted goodness-of-fit index; TLI - Tucker-Lewis index; CFI - comparative fit index; RMSEA - root-mean-square error of approximation. Most restrictive model with a good fit is in italics.

${ }^{*} p<.05,{ }^{* *} p<.01,{ }^{* * *} p<.001$.

Fit indices of AGFI, TLI, and CFI acceptable at values of .90 and higher; RMSEA acceptable with values of .80 and less (Hoyle, 1995).

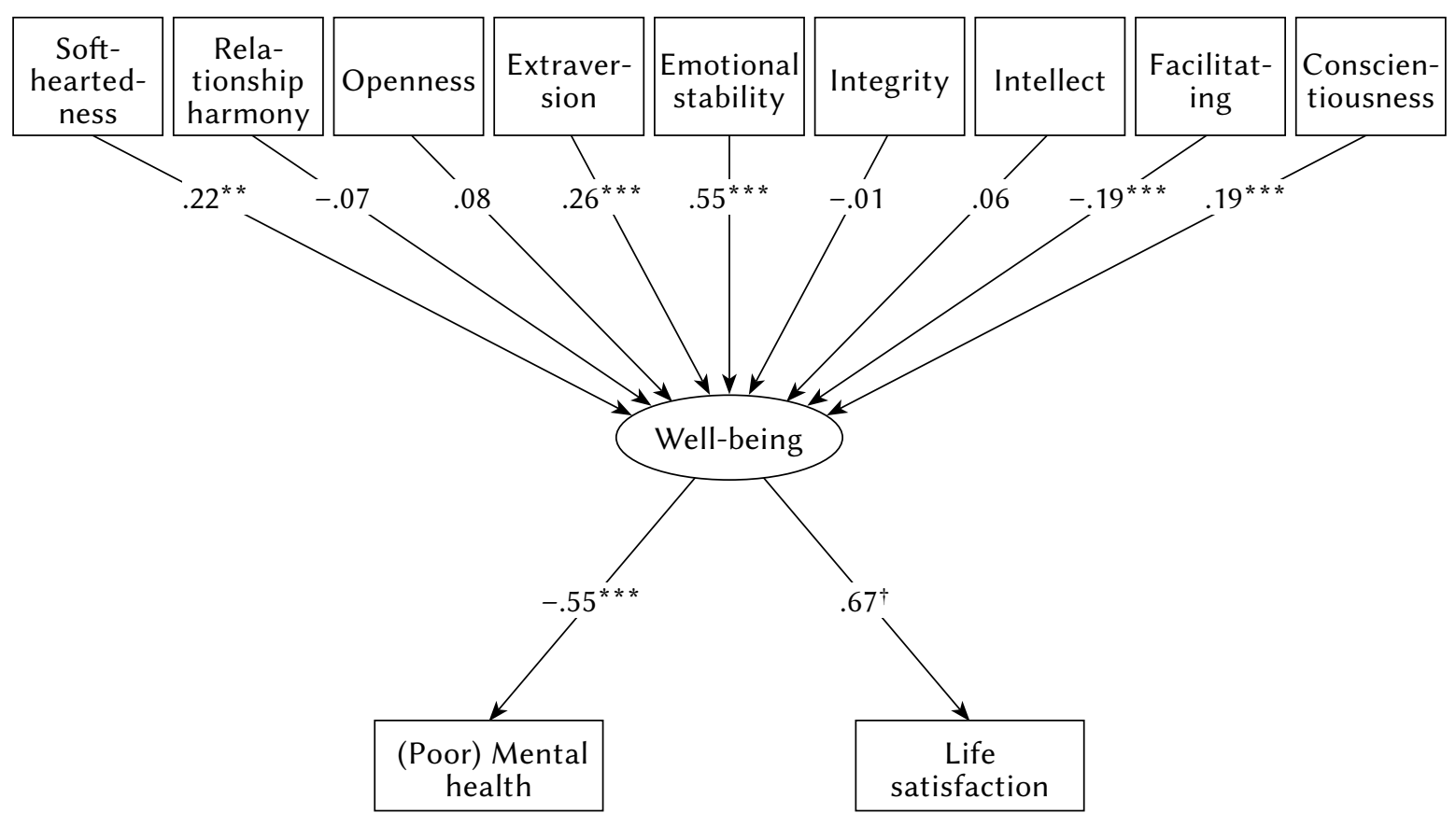

${ }^{* *} p<.01,{ }^{* * *} p<.001$. Indicates constraint set to 1 in unstandardized model.

Figure 1. Personality and well-being. 
adults in South Africa. It was evident that there were significant differences in all personality factors across Black and White emerging adults when reviewing the mean scores, except for integrity. We found that Black and White emerging adults have similar moralistic perceptions pertaining to their outlook and society. However, as stated before, more apparent differences were identified. From the results it can be construed that Black emerging adults are more inclined to be meticulous, thorough, and scored higher on intellect. These are typical characteristics relevant for work-related elements, and are individualistic in orientation. Furthermore, it seems that the Black emerging adults shows higher probability of being guiding, advising, and having openness for new experiences which are more relevant towards collectivistic cultures. This is in line with studies done by Feldman and Msibi (2014), Govind (2015) and Donoghue, Strydom, Andrews, Pentecost, \& De Klerk (2015) where they found that Black individuals in South Africa seem to encompass a combination of individualistic and collectivistic elements.

It seems the White emerging adults are more sociable, caring, friendly, emotionally balanced and maintain good relations based on the findings of this study. These findings are interesting since collectivistic features are found to be more prominent in the White emerging adults. However, as can be seen from the previous paragraph, it seems that both ethnic groups comprise pre-dominant social-relational features, while more individualistic features are identified in the Black ethnic group.

Pertaining to well-being, it seems that both Black and White emerging adults experience mental health the same way. No distinction was identified. However, it seems that White emerging adults experience more general fulfilment with their lives than the Black emerging adults. This may be related to the current situation with youth in South Africa where the tertiary education system saw eruptions across the country because of language policies (i.e., Afrikaans as the instruction language) and racial unrest (Harvergal, 2016).

\section{PERSONALITY AND WELL-BEING}

Next we assessed the relationship between personality and well-being in a multigroup analysis. We used well-being as a latent variable (indicated by life satisfaction and poor mental health) in order to ascertain which SAPI factors influence overall well-being. It was found that four factors positively influenced well-being, namely conscientiousness, emotional stability, extraversion and soft-heartedness. This is in line with the studies of Erdogan and colleagues (2012) and Bruwer (2016). It seems that the more thorough, meticulous, emotionally balanced, sociable, and ami- able emerging adults are, the more well-being they experience. If we review these traits, it seems that emerging adults who exhibit both organizational and social features may enjoy more well-being than others (Erdogan et al., 2012). On the other hand, from the findings it seems that facilitating as an SAPI factor negatively predicts well-being. This means the less guidance and advice emerging adults provide to others, the healthier they are. Since we tested emerging adults, it may be that those features are not so important to sustain well-being during their current life phase, and it will negatively affect their well-being when they need to exhibit elements associated with the cluster of facilitating.

It was found that integrity, intellect, openness and relationship harmony showed no prediction for well-being. Bruwer (2016) used the SAPI and found similar results pertaining to integrity and relationship harmony in her study. She found that social-relational elements overall showed little to no correspondence to well-being outcomes. However, she did find that intellect and openness showed links to health which contradict the current study outcomes. It seems that being open and inquisitive does not affect emerging adults' overall well-being. Bruwer's (2016) study included all age groups, and the inference can be made that different generations experience well-being differently pertaining to aspects of intellect and openness.

\section{LIMITATIONS AND RECOMMENDATIONS}

This study was not without limitations. Using a cross-sectional design means that causal relationships between personality and well-being cannot be assessed. Additionally, only two of the four South African ethnocultural groups formed part of this study, so no definite inferences can be generalized towards all emerging adults. The White ethnocultural group consisted of more participants $(n=600)$ than the Black ethnocultural group $(n=390)$. This is the case since tertiary institutions that were targeted included more White ethnic emerging adults than Black ethnic emerging adults. It corresponds with the latest Census (Statistics South Africa, 2011). The 82-item SAPI seemed to show evidence of low internal consistency in a previous study (Nel et al., 2015), while the reliability improved in the current study. A more rigorous analysis of the items needs to be conducted in order to determine items that shows bias and inequivalence in their measurement.

Recommendations for future studies will now be stipulated. Future studies should include the other two ethnocultural groups (Asian/Indian and Coloured) in order to make more inferences regarding ethnocultural similarities and differences pertaining to personality and well-being. A longitudinal 
study will be more applicable in order to assess the long-standing effects of personality features on well-being. Item analysis on the 82 -item version of the SAPI can use Differential Item Functioning (DIF) as an evaluation technique in order to detect distinctions in the understanding of the items between the different ethnocultural groups. That is because this study showed differences in personality between the two ethnocultural groups. This should be kept in mind with future SAPI studies when making inferences. The Employment Equity Act states clearly that all measurements should be unbiased and show equivalence in measurement. Since organizational-related and social-relational traits were found to influence well-being of emerging adults, intervention programmes can be implemented in order for emerging adults to become aware of their own personality profiles and their effect on their overall well-being.

\section{CONCLUSIONS}

This study made a significant contribution towards personality psychology and well-being research in cross-cultural South Africa. The findings of this study showed surprising elements between Black and White emerging adults, since it was found that emerging adults' personality is structured differently between Black and White participants. More specifically, it seems that Black emerging adults showed more individualistic than collectivistic characteristics than White emerging adults. These findings contribute to building the nomological network of the SAPI and expanding our knowledge pertaining to our notion of individualistic and collectivistic compositions of personality in cross-ethnic studies. It was found further that White emerging adults experience well-being more than Black emerging adults. These health differences should be acknowledged, especially concerning the current social and political circumstances of South Africa (Harvergal, 2016).

\section{References}

Adams, B. G., van de Vijver, F. J. R., \& De Bruin, G. P. (2012). Identity in South Africa: Examining self descriptions across ethnic groups. International Journal of Intercultural Relations, 30, 377-388.

Anglim, J., \& Grant, S. (2014). Predicting psychological and subjective well-being from personality: Incremental prediction from 30 facets over the Big 5. Journal of Happiness Studies, 15, 1-22. doi: 10.1007/s10902-014-9583-7

Black, S. A., \& Porter, L. J. (1996). Identification of the critical factors of TQM. Decision Sciences, 27, 1-21.

Bollen, K. A. (1989). Structural equations with latent variables. New York, NY: Wiley.
Booysen, L. (2001). The duality in South African leadership: Afrocentric or Eurocentric. South African Journal of Labour Relations, 25, 36-64.

Bruwer, M. (2016). Assessing the nomological network of the South African Personality Inventory (Unpublished master's dissertation). North-West University, Potchefstroom, South Africa.

Cropanzano, R., \& Dasborough, M. T. (2015). Dynamic models of well-being: Implications of affective events theory for expanding current views on personality and climate. European Journal of Work and Organizational Psychology, 24, 844-847. doi: 10.1080/1359432X.2015.1072245

Dempster, A. P., Laird, N. M., \& Rubin, D. B. (1977). Maximum Likelihood from Incomplete Data via the EM Algorithm. Journal of the Royal Statistical Society, 39, 1-38.

De Raad, B., Barelds, D. P. H., Timmerman, M. E., De Roover, K., Mlacic, B., \& Church, A. T. (2014). Towards a Pan-cultural Personality Structure: Input from 11 psycholexical studies. European Journal of Personality, 28, 497-510.

Donoghue, S., Strydom, N., Andrews, L., Pentecost, R., \& De Klerk, H. M. (2015). Differences between Black and White South Africans in product failure attributions, anger and complaint behaviour. International Journal of Consumer Studies, 40, 257-267.

Ebrahim, A., Botha, F., \& Snowball, J. (2013). Determinants of life satisfaction among race groups in South Africa. Development Southern Africa, 30, 168-185. doi: 10.1080/0376835X.2013.797227

Erdogan, B., Bauer, T. N., Truxillo, D. N., \& Mansfield, L. R. (2012). Whistle while you work: A review of the life satisfaction literature. Journal of Management, 38, 1038-1083. doi: 10.1177/ 0149206311429379

Feldman, A., \& Msibi, S. (2014). Influence of crosscultural leadership on organizational culture: Arcelormittal, Newcastle, a South African perspective. African Journal of Hospitality, Tourism and Leisure, 3, 1-9.

Fetvadjiev, V. H., Meiring, D., van de Vijver, F. J. R., Nel, J. A., \& Hill, C. (2015). The South African Personality Inventory (SAPI): An Indigenous Personality Tool for the Country's Main Ethnocultural Groups. Psychological Assessment, 27, 827-837. doi: 10.1037/pas0000078

Goldberg, D. (1972). The detection of psychiatric illness by questionnaire: A technique for the identification and assessment of non-psychotic psychiatric illness. London, United Kingdom: Oxford University Press.

Govind, S. (2015). The leadership experience: An example of in the Life Assurance sector in South Africa (Unpublished master's dissertation). University of Johannesburg, Johannesburg, South Africa.

Harvergal, C. (2016, February 24). ANC condemns latest unrest at South Africa's universities. Retrieved from https://www.timeshighereducation. 
com/news/anc-condemns-latest-unrest-south-africas-universities.

Heuchert, J., Parker, W., Stumpf, H., \& Myburgh, C. (2000). The five-factor model of personality in South African college students. American Behavioral Scientist, 44, 112-125. doi: 10.1177/00027640021956125

Hill, C., Nel, J. A., van der Vijver, F. J. R., Meiring, D., Valchev, V. H., Adams, B. G., \& de Bruin, G. P. (2013). Developing and testing items for the South African personality inventory (SAPI). South African Journal of Industrial Psychology, 39, 2-27.

Hoyle, R. H. (ed.). (1995). Structural equation modeling: Concepts, issues, and applications. London, United Kingdom: Sage Publications.

Hu, L., \& Bentler, P. M. (1999). Cutoff criteria for fit indexes in covariance structure analysis: Conventional criteria versus new alternatives. Structural Equation Modeling, 6, 1-55.

Huebner, E. S., Nagle, R. J., \& Suldo, S. M. (2003). Quality of life assessment in child and adolescent health care: The Multidimensional Students' Life Satisfaction Scale (MSLSS). In J. Sirgy, D. Rahtz, \& A. C. Samli (eds.), Advances in Quality-of-Life Theory and Research (pp. 179-190). Dordrecht, The Netherlands: Kluwer Academic Press.

Klimstra, T. A., Luyckx, K., Hale, W. W., III, Meeus, W. H. J., van Lier, P. A. C., \& Frijns, T. (2010). Shortterm fluctuations in identity: Introducing a micro-level approach to identity formation. Journal of Personality and Social Psychology, 99, 191-202.

Laher, S. (2013). Understanding the Five-Factor Model and Five-Factor Theory through a South African cultural lens. South African Journal of Psychology, 43, 208-221.

Laher, S., \& Cockcroft, K. (2014). Psychological assessment in post-apartheid South Africa: The way forward. South African Journal of Psychology, 44, 303-314.

Lance, C. E., Butts, M. M., \& Michels, L. C. (2006). The sources of four commonly reported cutoff criteria what did they really say? Organizational Research Methods, 9, 202-220. doi: $10.1177 / 1094428105284919$

Lee, K., \& Ashton, M. C. (2008). The HEXACO personality factors in the indigenous personality lexicons of English and 11 other languages. Journal of Personality, 76, 1001-1053.

Matsimbi, W. E. (1997). Cross-cultural generalisability of the five-factor-model: A study on South African white collar males (Unpublished master's dissertation). University of Witswatersrand, Johannesburg, South Africa.

Meiring, D., van de Vijver, F. J. R., \& Rothmann, S. (2006). Bias in an adapted version of the 15FQ+ in RSA. South African Journal of Psychology, 36, 340-356.

Meiring, D., van de Vijver, A. J. R., Rothmann, S., \& Barrick, M. R. (2005). Construct, item, and method bias of cognitive and personality measures in South Africa. South African Journal of Industrial Psychology, 31, 1-8.

Neff, D. F. (2007). Subjective well-being, poverty and ethnicity in South Africa: Insights from an exploratory analysis. Social Indicators Research, 80, 313-341.

Neill, J. (2003). Personality and individual differences: An undergraduate psychology course. Retrieved from http://www.wilderdom.com/personality/intelligence.html.

Nel, J. A., Fetvadjiev, V. H., Rothmann, S., van de Vijver, F. R. J., Meiring, D., \& Hill, C. (2016). Developing psychometric instruments for a specific context: The South African Personality Inventory. In R. Ferreira (ed.), Thinking innovatively about psychological assessment in a context of diversity (pp. 86-101). Cape Town, South Africa: Juta.

Nel, J. A., Valchev, V. H., Rothmann, S., van de Vijver, F. J. R., Meiring, D., \& De Bruin, G. P. (2012). Exploring the personality structure in the 11 languages of South Africa. Journal of Personality, 80, 915-948. doi: 10.1111/j.1467-6494.2011.00751.x

Nel, N., Nel, J. A., Adams, B. G., \& De Beer, L. T. (2015). Assessing cultural intelligence, personality and identity amongst young white Afrikaans-speaking students: A preliminary study. South African Journal of Human Resource Management, 13, 1-12.

Ozer, D. J., \& Benet-Martinez, V. (2006). Personality and the prediction of consequential outcomes. Annual Review of Psychology, 57, 401-421. doi: 10.1146/annurev.psych.57.102904.190127

Posel, D., \& Casale, D. (2016). Differences in subjective well-being within households: An analysis of married and cohabiting couples in South Africa. African Review of Economics and Finance, 7, 32-52.

Ramsay, L. J., Taylor, N., De Bruin, G. P., \& Meiring, D. (2008). The Big Five personality factors at work: A South African validation study. In J. Deller (ed.), Research contributions to personality at work (pp. 99-114). Munich, Germany: Rainer Hampp Verlag.

Saucier, G., \& Goldberg, L. (2001). Lexical studies of indigenous personality factors: Premises, products, and prospects. Journal of Personality, 69, 847-879. http://doi.org/10.1111/1467-6494.696167

Schatz, E., Angotti, N., Madhavan, S., \& Sennott, C. (2015). Working with teams of "insiders": qualitative approaches to data collection in the Global South. Demographic Research, 32, 369-396.

Schwartz, S. J., Beyers, W., Luyckx, K., Soenens, B., Zamboanga, B. L., Forthun, L. F., Hardy, S. A., Vazsonyi, A. T., Ham, L. S., Kim, S. Y., Whitbourne, S. K., \& Waterman, A. S. (2011). Examining the light and dark sides of emerging adults' identity: A study of identity status differences in positive and negative psychosocial functioning. Journal of Youth and Adolescence, 40, 839-859. 
Seligman, M. E. P. (2012). Flourishing: A visionary new understanding of happiness and well-being. New York, NY: Free Press.

Statistics South Africa. (2011). Census 2011. Retrieved from http://www.statssa.gov.za/publications

Steel, P., Schmidt, J., \& Shultz, J. (2008). Refining the relationship between personality and subjective well-being. Psychological Bulletin, 134, 138-161.

Taylor, I. A. (2000). The construct comparability of the NEO-PI-R questionnaire for black and white employees (Unpublished doctoral thesis). University of the Free State, Bloemfontein, South Africa.

Taylor, N., \& De Bruin, G. P. (2005). Manual of the Basic Traits Inventory. Johannesburg, South Africa: JvR.

Valchev, V. H., Nel, J. A., van de Vijver, F. J. R., Meiring, D., De Bruin, G. P., \& Rothmann, S. (2013). Similarities and differences in implicit personality concepts across ethno-cultural groups in South Africa. Journal of Cross-Cultural Psychology, 44, 365-388. doi: 10.1177/0022022112443856

Valchev, V. H., van de Vijver, F. J. R., Nel, J. A., Rothmann, S., Meiring, D., \& De Bruin, G. P. (2011). Implicit personality conceptions of the Nguni cultural-linguistic groups of South Africa. CrossCultural Research, 45, 235-266. doi: 10.1177/10693 97111402462

Van de Vijver, F. J. R., \& Leung, K. (1997). Methods and data analysis for cross-cultural research. Newbury Park, CA: Sage.

Van Jaarsveld, W. (2015). Testing a leadership model among managers (Unpublished master's dissertation). North-West University, Potchefstroom, South Africa.

Van Zyl, C. J. (2014). The psychometric properties of the Emotional Quotient Inventory 2.0 in South Africa: Original research. South African Journal of Industrial Psychology, 40, 1-8.

Wallis, T., \& Birt, M. (2003). A comparison of native and non-native English-speaking groups' understanding of the vocabulary contained in the 16PF (SA92). South African Journal of Psychology, 33, 182-190. 